\title{
Using Dual Microresonant Cavity and Plasmonic Effects to Enhance the Photovoltaic Efficiency of Flexible Polymer Solar Cells
}

\author{
Wenfei Shen ${ }^{1, *} \mathbb{C}$, Guoqing Zhao ${ }^{2}$, Xiaolin Zhang ${ }^{1}$, Fanchen Bu ${ }^{1}$, Jungheum Yun ${ }^{2, *}$ and \\ Jianguo Tang ${ }^{1, * \mathbb{D}}$ \\ 1 Institute of Hybrid Materials, National Center of International Joint Research for Hybrid Materials \\ Technology, National Base of International Science \& Technology Cooperation on Hybrid Materials, \\ College of Materials Science and Engineering, Qingdao University, 308 Ningxia Road, Qingdao 266071, \\ China; xiaolinzhang0307@126.com (X.Z.); bufanchen95@163.com (F.B.) \\ 2 Surface Technology Division, Korea Institute of Materials Science, Changwon, Gyeongnam 51508, Korea; \\ zhaogq@kims.re.kr \\ * Correspondence: shenwenfei@qdu.edu.cn (W.S.); jungheum@kims.re.kr (J.Y.); tang@qdu.edu.cn (J.T.)
}

Received: 17 April 2020; Accepted: 14 May 2020; Published: 15 May 2020

\begin{abstract}
Fabricating polymer solar cells (PSCs) on flexible polymer substrates, instead of on hard glass, is attractive for implementing the advantage and uniqueness of the PSCs represented by mechanically rollable and light-weight natures. However, simultaneously achieving reliable robustness and high-power conversion efficiency (PCE) in such flexible PSCs is still technically challenging due to poor light harvesting of thin photoactive polymers. In this work, we report a facile, effective strategy for improving the light-harvesting performance of flexible PSCs without sacrificing rollability. Very high transparent $(93.67 \%$ in $400-800 \mathrm{~nm})$ and low sheet resistance $\left(\sim 10 \Omega \mathrm{sq}^{-1}\right) \mathrm{ZnO} / \mathrm{Ag}_{(\mathrm{O})} / \mathrm{ZnO}$ electrodes were implemented as the flexible substrates. In systematically comparison with $\mathrm{ZnO} / \mathrm{Ag} / \mathrm{ZnO}$ electrodes, small amount of oxygen induced continuous metallic films with lower thickness, which resulted in higher transmittance and lower sheet resistance. To increase the light absorption of thin active layer (maintain the high rollability of active layer), a unique platform simultaneously utilizing both a transparent electrode configuration based on an ultrathin oxygen-doped $\mathrm{Ag}, \mathrm{Ag}(\mathrm{O})$, and film and plasmonic Ag@SiO 2 nanoparticles were designed for fully leveraging the advantages of duel microresonant cavity and plasmonic effects to enhance light absorbance in photoactive polymers. A combination of the $\mathrm{ZnO} / \mathrm{Ag}_{(\mathrm{O})} / \mathrm{ZnO}$ electrode and $\mathrm{Ag} @ \mathrm{SiO}_{2}$ nanoparticles significantly increased the short-current density of PSCs to $17.98 \mathrm{~mA} \mathrm{~cm}^{-2}$ with enhancing the photoluminescence of PTB7-Th film. The flexible PSC using the optimized configuration provided an average PCE of $8.04 \%$ for flexible PSCs, which was increased by $36.27 \%$ compared to that of the PSC merely using a conventional transparent indium tin oxide electrode.
\end{abstract}

Keywords: flexible polymer solar cells; oxide/metal/oxide electrode; microresonant cavity; plasmonic; light absorption

\section{Introduction}

Great progress in polymer solar cells (PSCs) has been achieved via state-of-the art fabrication techniques utilizing novel donor and acceptor materials [1-3]. PSCs supported on flexible transparent polymer substrates offer the merits of light weight and flexibility over inorganic solar cells [4]. The merits enable the fabrication of PSCs using facile, cost-effective roll-to-roll processes [5,6]. However, highly efficient PSCs are still challenging to obtain on polymer substrates owing to their photocurrent conversion performance (PCE) clearly being inferior than those of their inorganic counterparts. 
Extensive research efforts have been devoted toward enhancing light trapping and absorption in the photoactive layers of PSCs by employing various optical manipulation techniques [7-13].

Implementing a highly efficient transparent conductive electrode (TCE) on polymer substrates is taken into account as a primary task to resolve the issue [5,14-21]. Typical oxide-based TCEs, represented by indium tin oxide (ITO), in an amorphous phase exhibit seriously reduced electrical conductivity and optical transparency on the polymer substrates. Although notable improvements in their photoelectrical properties require applying either an elevated crystallization temperature or an increased thickness, but such options are unsuitable because of the thermal damage of heat-sensitive polymers and mechanical brittleness of thick oxides on mechanically flexible polymers [5,22]. Extensive research efforts were directed at substituting ITO with more effective TCE alternatives that exhibit improved electrical conductivity and optical transparency, high structural durability against severe mechanical deformation, long-term chemical stability, and near room temperature fabrication [7,23-28]. Patterned or irregular nanometal meshes are widely accepted as promising flexible TCEs, for instance, Jung-Yong Lee reported a $>10 \%$ PCE by using metal nanonetworks as transparent electrode [23]. However, patterned or irregular nanometal meshes are excluded from consideration because the one-dimensional geometry of the metal meshes must be further combined with conductive polymers to achieve an uniform current extraction from the entire area of PSCs. Meanwhile, continuous thin films of coinage metals (i.e., $\mathrm{Ag}$, $\mathrm{Au}$, and $\mathrm{Cu}$ ) sandwiched between oxide films in an oxide/metal/oxide $(\mathrm{OMO})$ configuration have drawn attention as promising TCE candidates for PSCs with their excellent photoelectric properties, mechanical flexibilities, and anticorrosion performances [5,15-17,29-31]. Recently, highly efficient OMOs using an ultrathin $\mathrm{Ag}$ or $\mathrm{Cu}$ film were developed with a special emphasis on high optical transparency. A complete continuous film geometry of such noble metals at significantly reduced thicknesses was found to form with an enhanced wetting via a simple gas-additive-induced tailoring of the growth of noble metals on oxides. The OMOs exhibited greatly improved optical transparencies in the visible spectral range $(400-800 \mathrm{~nm})$ while maintaining lower sheet resistances, relative to those of conventional amorphous ITOs fabricated on polymers, for instance, $\mathrm{ZnO} / \mathrm{Cu} / \mathrm{ZnO}$ with $86 \%$ average total transmittance exhibits a sheet resistance of $\sim 10 \Omega \mathrm{sq}^{-1}$ much lower than that of ITO with $\sim 30 \Omega \mathrm{sq}^{-1}$ sheet resistance (along with $83 \%$ average total transmittance), as result, the PCE can be over $8 \%$. Flexible PSCs utilizing the OMOs as their front electrodes exhibited highly improved power conversion efficiencies compared to that of PSCs utilizing ITOs, while still lower than that of the same PSCs fabricated on glasses coated with crystalline ITOs. Considering the relatively low light absorption in the thin photoactive polymer layer of PSCs as the primary reason for their inferior PCEs, a further PCE improvement is readily anticipated for the PSCs by improving the light absorption in the photoactive layer via use of light-controlling techniques other than an increase in the photoactive layer that causes severe charge carrier extinction due to their low mobility and short diffusion of charge carriers in photoactive polymers.

Light manipulation techniques are effective to enhance the light trapping and absorption in photoactive layers of PSCs. Classical light manipulation techniques including antireflection structure, substrate geometry-induced trapping, plasmonic effects, optical microcavity resonance and so on, and various technologies exhibited light trapping improvements [32,33]. As one of the most studied technologies for light manipulation, the plasmonic effects of metallic nanoparticles (MNPs) are exhibited by various mechanisms, i.e., near-field enhancements (localized surface plasmon resonance, LSPR), far-field scattering, and resonant hot electron energy transfer [34]. Researchers generally agree that the plasmonic effect induced by LSPR and light scattering of metallic nanoparticles can be applied to photovoltaic devices to enhance the PCE performances [35,36]. The metallic nanoparticles can be incorporated to various layers of devices, for instance, hole transport layer, electron transport layer, and active layer. According to the mechanism of LSPR effect, indicating that the magnified electromagnetic field intensity decays with increasing the distance from nanometallic surface, incorporating MNPs into the photoactive layer is surely beneficial for the light absorption owing to the magnified electromagnetic field. As efforts to enhance the PCE of PSCs, $\mathrm{SiO}_{2}$-encapulated MNPs were successfully applied while 
avoiding exciton quenching by naked MNPs, which directly degrade the photovoltaic performance of PSCs. Meanwhile, implementing optical microresonant cavity may further improve the light absorbance in the photoactive layer by trapping optical light in the layer [35-37]. The enhancement in the photovoltaic performance of PSCs, either on glass or polymer substrates, was successfully achieved by realizing the virtue of the microresonant cavity effect. Jung et al. fabricated a 3D microresonant cavity system by nanopatterning processes on PET substrate and reported an improved PCE that was increased by $26.4 \%$ owing to the enhanced light absorption and charge collection efficiency. Jen et al. enhanced light absorption and photovoltaic performance by integrating the microcavity effect to flexible PSCs using Ag nanoplates on top and back electrodes [38,39]. By carefully investigation and calculations, Kim et al. presented experimental and numerical evidences indicating that the effect of microresonant cavity phenomena is confined to an interstitial medium between two metals [35] and the intensity of the optical field inside the cavity is much larger than that of the incident field [40]. Therefore, it is reasonable to believe that there are microresonant cavity phenomena between OMO electrode and metal electrodes, which can increase the light path, thus increase the light absorption.

Comprehensively implementing the dual effects of plasmonic effect and microresonant cavity effects in flexible PSCs structures, light absorption may be greatly improved by the magnified electromagnetic field and enlarged light paths, and this will provide a way to enhance the photovoltaic performances of PSCs on flexible substrates. In this work, we integrated the dual effects of the LSPR of MNPs and microresonant cavity to flexible PSCs devices. As a result, we successfully achieved the average PCEs of $8.04 \%$, which increased by $36.27 \%$ compared to that of a flexible PSC using a conventional ITO, with a significantly improved photocurrent density. $\mathrm{ZnO} / \mathrm{Ag} / \mathrm{ZnO}$ and $\mathrm{ZnO} / \mathrm{Ag}_{(\mathrm{O})} / \mathrm{ZnO}\left(\mathrm{Ag}_{(\mathrm{O})}\right.$ : oxygen-doped $\left.\mathrm{Ag}\right) \mathrm{OMO}$ electrodes were comparatively studied by optimizing the thickness of metallic layer on the properties of transmittance, conductivity, and photovoltaic performances. In addition, the improved photovoltaic performances were ascribed to the improved total transmittance and conductivity with the incorporation of oxygen in Ag layer. Besides, the concentration of $\mathrm{Ag} @ \mathrm{SiO}_{2}-\mathrm{NPs}$ incorporated in the photoactive layer was optimized by enhancing the light absorption with the incorporation of $\mathrm{Ag} @ \mathrm{SiO}_{2}-\mathrm{NPs}$. Improving light absorption was confirmed by clear evidences of the enhancement in the photoluminescence intensity of pure PTB7-Th film and PTB7-Th film with nanoparticles.

\section{Experiment Details}

\subsection{Preparation of OMO Electrodes}

The OMO electrodes were fabricated on a $125-\mu \mathrm{m}$ thick, transparent poly(ethylene terephthalate) (PET) substrates (Panac Co., Ltd., Shenzhen, China) via a sequential magnetron sputtering processes at room temperature using a magnetron multigun sputtering system (A-Tech System Co., Ltd., FlexLab system 100, Taichung City, Taiwan). The ZnO layers (40 nm) were deposited from a 4 in. ZnO target (99.999\% purity, Applied Science Co., Paju, Korea) at a working pressure of $4.0 \times 10^{-4}$ pa using a radio frequency plasma power of $200 \mathrm{~W}\left(0.53 \mathrm{~W} \mathrm{~cm}^{-2}\right)$, and no intentional thermal annealing were implemented for the $\mathrm{ZnO}$ layers prior to and post the deposition. $\mathrm{Ag}$ and $\mathrm{Ag}(\mathrm{O})$ layers were deposited on the bottom $\mathrm{ZnO}$ layer with different thicknesses between 6 and $15 \mathrm{~nm}$ using a reactive sputtering process at a direct current power of $50 \mathrm{~W}\left(0.13 \mathrm{~W} \mathrm{~cm}^{-2}\right)$. A 4 in. Ag target $(99.99 \%$ purity, Applied Science Co.) was sputtered at $4.0 \times 10^{-4} \mathrm{~Pa}$ under a mixed $\mathrm{Ar}: \mathrm{O}_{2}$ gas atmosphere at a flow rate of 45:4 $\mathrm{sccm}$. The oxygen concentration incorporated in Ag was determined to be about 3 at $\%(\mathrm{O} / \mathrm{Ag}$ atom ratio). Then, a $40 \mathrm{~nm}$ thick $\mathrm{ZnO}$ was redeposited. As for comparison, a $120 \mathrm{~nm}$ thick ITO electrode on flexible PET substrates were prepared using an $\operatorname{In}_{2} \mathrm{O}_{3}$ target (Applied Science Co.) with $10 \mathrm{wt} \%$ $\mathrm{Sn}$. In addition, $40 \mathrm{~nm} \mathrm{ZnO}$ was deposited on ITO electrode to obtain same surface condition with OMO electrodes. 


\subsection{Preparation of Polymer Solar Cell Devices}

The inverted device structure of $\mathrm{PET} / \mathrm{ZnO} / \mathrm{Ag}_{(\mathrm{O})} / \mathrm{ZnO} /$ Active layer/PEDOT:PSS/Ag were shown in Figure 1a. Once the flexible, high transparent $\mathrm{ZnO} / \mathrm{Ag}_{(\mathrm{O})} / \mathrm{ZnO}$ films were prepared on PET substrates, the photoactive polymer layer was directly coated on the OMO without adding carrier transport materials because of the electron transport performance of the $\mathrm{ZnO}$ top layer in the OMO electrodes. For preparing photoactive layer with metallic nanoparticle, $\mathrm{Ag} @ \mathrm{SiO}_{2}-\mathrm{NPs}$ were prepared by wet chemical method, with two steps. First, silver nanoparticles were synthesized at $100{ }^{\circ} \mathrm{C}$ with water as solvent, $\mathrm{PVP}$ as surfactant, trisodium citrate and glucose as additives, and $\mathrm{NH}_{4} \mathrm{OH}$ as reductant. Second, $\mathrm{SiO}_{2}$ shell were synthesized by modified Stöber method with ethanol and water $(9: 1$, volume ratio) as solvent, $\mathrm{NH}_{3}$ as reductant, $0.011 \mathrm{~mol}$ TEOS diluted in $50 \mathrm{~mL}$ solvent, and reaction at $40^{\circ} \mathrm{C}$ for $2 \mathrm{~h}$. More detailed information can be found in our previous studies. Ag@ $\mathrm{SiO}_{2}-\mathrm{NPs}$ were treated with $\gamma$-glycidoxypropyltrimethoxysilane (50 vol. \% KH560) aqueous solution for $12 \mathrm{~h}$ to improve the dispersion of $\mathrm{Ag} @ \mathrm{SiO}_{2}-\mathrm{NPs}$ in the photoactive layer. The $\mathrm{Ag} @ \mathrm{SiO}_{2}-\mathrm{NPs}$ were washed and centrifuged 3 times, and dried in a vacuum oven at a low temperature; PTB7-Th and $\mathrm{PC}_{71} \mathrm{BM}$ were used as donor and acceptor materials, respectively. Ag@SiO $2-\mathrm{NPs}$ of $1.0 \mathrm{wt} \%$ were added in a PTB7-Th:PC ${ }_{71} \mathrm{BM} \mathrm{CB}$ solution $(1: 1.5,10 \mathrm{mg} / \mathrm{mL}$ for PTB7-Th, $3 \mathrm{vol} \%$ DIO as additive) to prepare the hybrid photoactive layer [41]. The dispersion of $\mathrm{Ag} @ \mathrm{SiO}_{2}-\mathrm{NPs}$ in the $\mathrm{CB}$ solution was improved by applying a 10-min ultrasonic treatment to the hybrid solution before its spin coating on the OMO electrode. A $3 \mathrm{~h}$ vacuum treatment $\left(4.0 \times 10^{-2} \mathrm{~Pa}\right)$ was implemented on the hybrid active layer to ensure the complete removal of the DIO in the photoactive layer and to fabricate the complete interpenetrating network for the photoactive layer [27]. The diluted PEDOT:PSS solution (1:10 by isopropyl alcohol) was dynamic spin coated on the photoactive layer as hole transport layer (with thickness of about $10 \mathrm{~nm}$ ). Lastly, A 100-nm Ag electrode was thermally evaporated onto the PEDOT:PSS layer at a working pressure of $5 \times$ $10^{-4} \mathrm{~Pa}$.

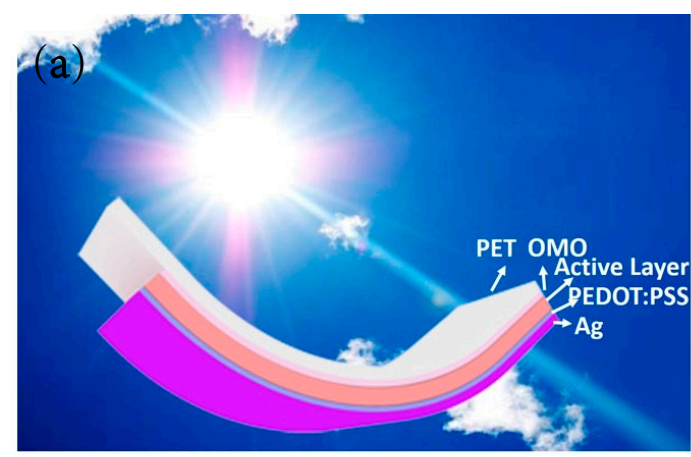

(c)
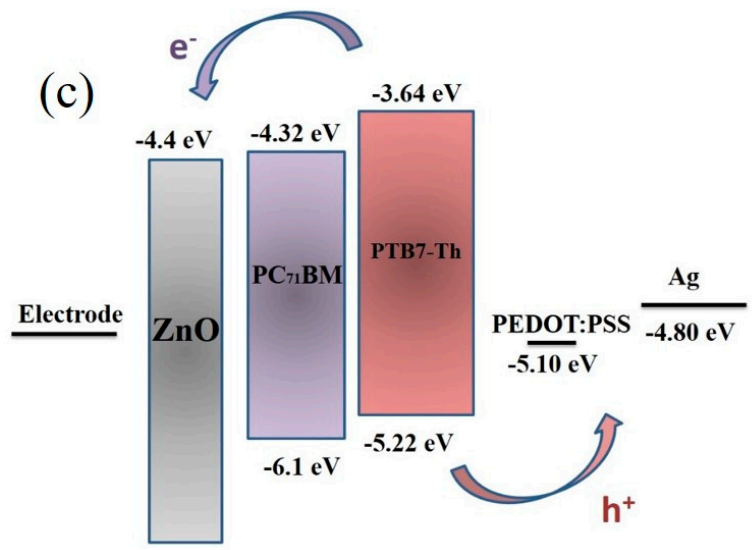

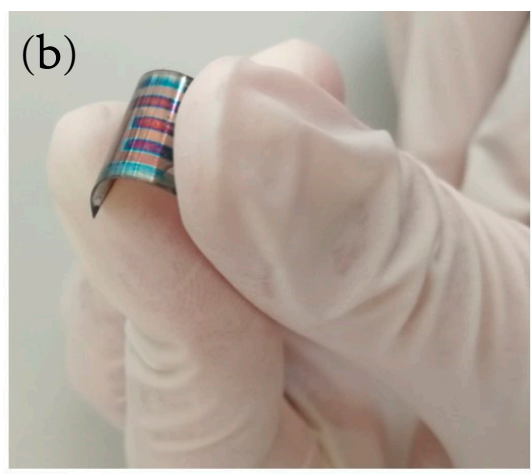

(d)

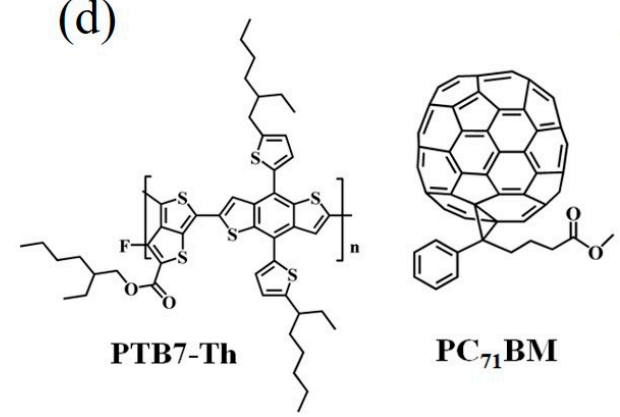

Figure 1. (a) The schematic diagram of inverted structure device, (b) the actual photo of flexible PSCs, (c) the energy levels of corresponding materials and electrodes utilized in PSCs devices, and (d) the chemical structure of PTB7-Th and $\mathrm{PC}_{71} \mathrm{BM}$. 


\subsection{Characterizations}

The transmission electron microscopy (TEM) image of $\mathrm{Ag} @ \mathrm{SiO}_{2}-\mathrm{NPs}$ was obtained using a JEM-2000 Ex system. The absorption spectra of Ag@SiO $-\mathrm{NPs}, \mathrm{PC}_{71} \mathrm{BM}$, and PTB7-Th were determined using a Varian Cary 50 UV-VIS spectrometer. The total transmittance spectra of PET substrate with various $\mathrm{Ag}_{(\mathrm{O})}$ thicknesses were determined using an UV-VIS spectrophotometer (equipped with integrated sphere, Cary 5000, Varian) with a normally incident radiation beam over the wavelength range of 320-800 $\mathrm{nm}$. The total transmittance was equal to Transmittance/(100\%-Reflection). The sheet resistances of OMO electrodes and ITO electrodes were determined using a four-point probe system (Mitsubishi Chemical Co., Tokyo, Japan, MCP-T600). The surface morphology of $10 \mathrm{~nm} \mathrm{Ag}(\mathrm{O})$ layer were observed using ultrahigh resolution field-emission scanning electron microscopy, UHR FE-SEM, (S-5500, Hitachi Co., Hong Kong, China). The current density-voltage (J-V) characteristics and the series resistance of devices were obtained by a Newport solar simulator using Keithley 2420 source measurement under AM 1.5 solar with intensity of $100 \mathrm{~mW} \cdot \mathrm{cm}^{-2}$. The external quantum efficiencies (EQE) of PSCs were determined using a certified Newport incident photon conversion efficiency (IPCE) measurement system. The photoluminescence spectra of PTB7-Th films were characterized by a FLS1000 Fluorescence Spectrometer (Edinburgh instruments Co., Livingston, UK). The active layer thicknesses can be quantified by the Veeco Dektak 150 surface profiler.

\subsection{Simulation}

The far field intensity near $\mathrm{Ag} @ \mathrm{SiO}_{2}-\mathrm{NPs}$ was calculated using a finite-difference time-domain (FDTD) method that was supplied by Optiwave. In the simulations, the size of core was chosen at $60 \mathrm{~nm}$, while the shell thickness was chosen at $10 \mathrm{~nm}$. The coated-sphere group structure was utilized; the core simulation materials was Ag (silver)_Johnson and Christy, while material used for shell was $\mathrm{SiO}_{2}$ (glass; with refractive index of 1.46)_Palik in the Material Database. In addition, the incident source was plane wave and corresponding wavelength was from 350 to $900 \mathrm{~nm}$, and the simulation region and maximum mesh step were $100 \mathrm{~nm} \times 100 \mathrm{~nm}$ and $1 \mathrm{~nm}$, respectively.

\section{Results and Discussion}

Dual effects of microresonant cavity and plasmonics were implemented by flexible PSCs in a structural configuration of PET/OMO/active layer/PEDOT:PSS/Ag (Figure 1a). The inverted structure of PSCs was considered in this study because of their multiple advantages. It is accepted to be more stable than the normal structure of PSCs with the virtue of the Ag electrode exhibiting a high work function [42]. Furthermore, the photocurrent density of inverted PSCs can be increased by applying the metal oxide $\left(\mathrm{ZnO}, \mathrm{TiO}_{2}\right.$, etc.) as an electron transport layer that exhibits a transmittance much higher than that of PEDOT:PSS in normal PSCs [5,43]. Here, no additional metal oxide layer is needed on the OMO electrode for transporting electron carriers because of the existence of the top ZnO layer in the OMO electrode. The superior mechanical flexibility of the PSC based on the OMO electrode is illustrated in Figure 1b. The energy levels of materials used in the PSC are illustrated in Figure 1c, and considering the relative thickness of $\mathrm{ZnO}$ layer, the work function of OMO electrode is difficult to measure, only $\mathrm{ZnO}$ energy level is demonstrated. When the chemical structures of PTB7-Th and $\mathrm{PC}_{71} \mathrm{BM}$ are schematically demonstrated in Figure $1 \mathrm{~d}$, the lowest unoccupied molecular orbit (LUMO) energy levels of PTB7-Th, $\mathrm{PC}_{71} \mathrm{BM}$, and $\mathrm{ZnO}$ are $-3.64,-4.32$, and $-4.4 \mathrm{eV}$, respectively. The appropriate difference between the energy levels of those materials provides favorable circumstances promoting the dissociation of excitons and the transport of electrons [44]. The highest occupied molecular orbit (HOMO) energy levels of PC 71 BM, PTB7-Th, PEDOT:PSS, and Ag which are approximated to be $-6.1,-5.22,-5.1$, and $-4.8 \mathrm{eV}$ [45], respectively, also provide favorable circumstances promoting the dissociation of excitons and the transport of holes $[44,46]$. The proposed structural configuration of PSCs provides an excellent chance of highly efficient photon-to-electron conversion [47]. 
The morphology of Ag-NPs was characterized because the plasmonic and scattering effects of metallic nanoparticles were strongly depending on the shape and size of the nanoparticles. Figure $2 \mathrm{a}$ shows the TEM image of $\mathrm{Ag} @ \mathrm{SiO}_{2}$-NPs that indicates total size of $65-80 \mathrm{~nm}$ with the core size of about $60-70 \mathrm{~nm}$ and the $\mathrm{SiO}_{2}$ shell thickness of about $5-10 \mathrm{~nm}$. We previously demonstrated that the contact of bare metallic nanoparticles with photoactive materials could cause exciton quenching. However, the existence of dielectric material, $\mathrm{SiO}_{2}$, could prevent effectively such the degradation in the photovoltaic performance by blocking the "hot electrons" from the contact to the photoactive materials [48]. The LSPR effect can be presented by the magnified electromagnetic field surrounding the nanoparticles, and the magnified electromagnetic field surely decays with an increased distance to nanoparticle surface. The computational results are shown in Figure $2 \mathrm{~b}$. Here, the LSPR effect was directly determined by FDTD simulations. The simulated far field intensity of $\mathrm{Ag} @ \mathrm{SiO}_{2}-\mathrm{NPs}$ is shown in the color image in which the colors represent the magnified electromagnetic field intensity [48]. The results indicated that the intensity of electromagnetic field can be magnified up to two to three times with the existence of $\mathrm{SiO}_{2}$ that does not block the magnified electromagnetic field. However, the intensity decays with increasing the distance from the surface of NPs. The magnified electromagnetic field extending to surroundings promotes the light absorption of the materials surrounding the $\mathrm{Ag} @ \mathrm{SiO}_{2}-\mathrm{NPs}$. Considering the existence of incorporated $\mathrm{Ag} @ \mathrm{SiO}_{2}-\mathrm{NPs}$, the thin $\mathrm{Ag}(\mathrm{O})$ layer, and the back Ag anode electrode in this work, it is reasonable to believe that there are three kinds of effects which will influence the light absorption or light path, as shown in Figure 2c, (1) LSPR effect, (2) scattering effects, and (3) microresonant cavity effects [33,49]. For LSPR effect, the light can be confined to a small space and the electromagnetic field can be magnified to several times, which will benefit the light absorption of donor/acceptor materials surrounding the NPs. As shown in Figure 2c, the light can be scattered by the NPs, which will increase the light path in the active layer, thus reasonably increase the light absorption. In addition, the existence of $\mathrm{Ag}_{(\mathrm{O})}$ thin layer $(\sim 7.5 \mathrm{~nm})$ and the back Ag anode electrode $(\sim 100 \mathrm{~nm})$ promise the presence of microresonant cavity, as shown in Figure 2c; although partial light go through thin $\mathrm{Ag}_{(\mathrm{O})}$ layer, most of light will oscillate in active layer between front and back electrodes, which greatly increase the light path, thus increase the light absorption. Considering the relatively small size of NPs, it is believed that the LSPR effect and microresonant cavity effect dominate the contributions of light absorption increments. Therefore, the light absorption of active layer in devices can be greatly increased with LSPR, scattering, and microresonant cavity effects $[35,48]$.

LSPR effect occurs when the incident light frequency is equal to the electron oscillation frequency on the metallic nanoparticle surface. To characterize the resonant light wavelength, UV-VIS absorptions of $\mathrm{Ag} @ \mathrm{SiO}_{2}-\mathrm{NPs}$ along with donor/acceptor materials were done, as shown in Figure 3. The relative strong light absorption for PTB7-Th is in the wavelength range of $600-750 \mathrm{~nm}$. The light absorption peak for $\mathrm{PC}_{71} \mathrm{BM}$ is $390 \mathrm{~nm}$, and the light absorption decay with the increase of wavelength. The LSPR wavelength is about $440 \mathrm{~nm}$, and the peak is not relatively wide, which is beneficial in the light absorption. Apart from the near-field enhancements that are caused by the magnified electromagnetic field, researchers also found that the light-induced excitons can combine with the resonance plasmons, which induces the light absorption ability go up to several times. Therefore, the plasmonic effect not only induces more photons confined in a small volume to increase the light absorption of materials surrounding metallic nanoparticles but also increases the light absorption ability of materials surrounding metallic nanoparticles. So, most importantly, the incorporation of $\mathrm{Ag} @ \mathrm{SiO}_{2}-\mathrm{NPs}_{\mathrm{s}}$ will increase the light absorption ability of photoactive materials in the range of $400-500 \mathrm{~nm}$, thus induce an enhancement of photovoltaic response in this range. 

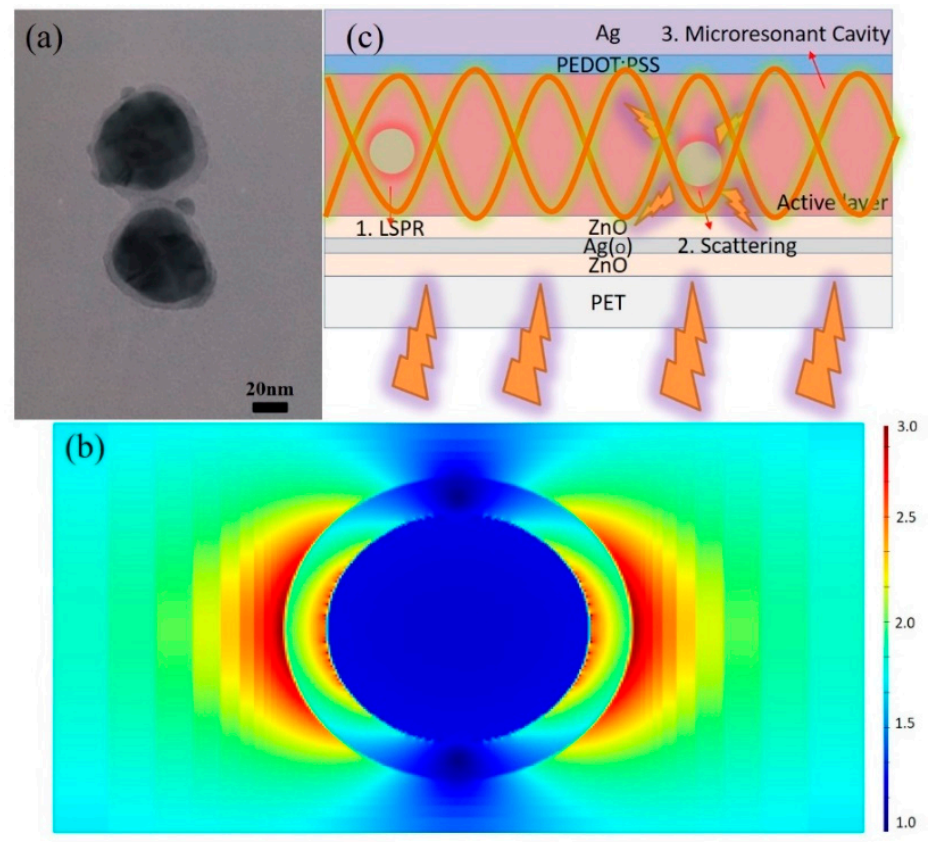

Figure 2. (a) The TEM image of $\mathrm{Ag} @ \mathrm{SiO}_{2}-\mathrm{NPs}$, (b) the FDTD simulation result of $\mathrm{Ag} @ \mathrm{SiO}_{2}-\mathrm{NPs}$, and (c) the enhancing mechanism by LSPR, scattering, and microresonant cavity effects.

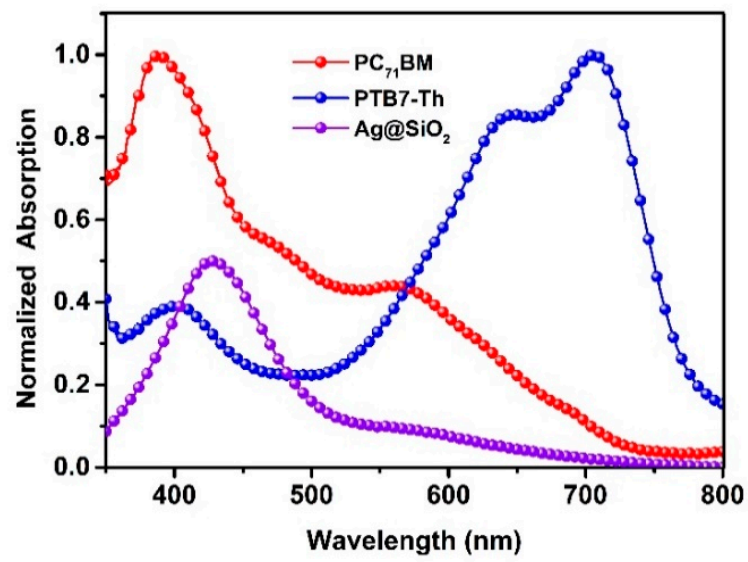

Figure 3. Light absorptions of $\mathrm{Ag@SiO}$-NPs solution in ethanol, and PTB7-Th solid film, PC 71 BM solid film.

To get higher photocurrent density and better charge extraction efficiency for devices on flexible substrates, relatively high transmittance and low sheet resistance are required for the OMO electrodes. In addition, in order to trap more photons by the microresonant cavity effects in active layer to realize better photovoltaic performance, the light transmittance should be maximized, which greatly depends on the thickness of metallic layer in OMO electrodes [50]. Therefore, first, $\mathrm{Ag}$ and $\mathrm{Ag}(\mathrm{O})$ thicknesses were optimized to systematically study the light transmittance property. To characterize the transmittance of OMO electrodes on PET substrates, total transmittances of 360-800 nm including scattering with various $\mathrm{Ag}$ and $\mathrm{Ag}_{(\mathrm{O})}$ thicknesses were done, as the results are shown in Figure $4 \mathrm{a}, \mathrm{b}$. From Figure $4 \mathrm{a}$, it can be seen that the transmittance of the $\mathrm{ZnO} / 9.0-\mathrm{nm} \mathrm{Ag} / \mathrm{ZnO}$ TCE reached 91.5\% at $550 \mathrm{~nm}$. Ag thickness between 6 and $7.5 \mathrm{~nm}$ shows a lower transmittance than that for $9.0 \mathrm{~nm}$, which can be ascribed to the light absorption and light scattering effects that are caused by the bigger nanoparticles of the uncontinuous thin film. The transmittance dramatically decreased from the maximum value with further increase in the thickness from $9.0 \mathrm{~nm}$. The optical loss was especially significant in the longer wavelengths over $600 \mathrm{~nm}$ mainly due to strong increase in the reflection 
with increase in the thickness. In Figure $4 \mathrm{~b}$, the total transmittance of $\mathrm{Ag}_{(\mathrm{O})} \mathrm{OMO}$ electrodes on PET substrates with 7.5 and $9.0 \mathrm{~nm}$ thicknesses is higher than that of $8 \mathrm{~nm} \mathrm{Ag}(\mathrm{O})$ OMO electrode on PET substrate in the wavelength range of 400-650 $\mathrm{nm}$ [51]. In the wavelength range more than $650 \mathrm{~nm}$, the total transmittance of 7.5 and $9.0 \mathrm{~nm}$ OMO electrodes is much lower than that of $8 \mathrm{~nm} \mathrm{Ag}_{(\mathrm{O})} \mathrm{OMO}$ electrode on PET substrate. Besides, the total transmittance of $12 \mathrm{~nm} \mathrm{Ag}(\mathrm{O})$ OMO electrodes on PET substrates decrease greatly in the wavelength range of 550-800 nm, and the total transmittance of $15 \mathrm{~nm}$ $\mathrm{Ag}_{(\mathrm{O})}$ OMO electrodes on PET substrates is much lower than that of substrates with thinner $\mathrm{Ag}_{(\mathrm{O})} \operatorname{layer}_{\text {, }}$ which is caused by the photon reflection of thick $\mathrm{Ag}_{(\mathrm{O})}$ layer. Generally, the overall total transmittance of $\mathrm{Ag}(\mathrm{O}) \mathrm{OMO}$ electrodes is better than that of $\mathrm{Ag}$ OMO electrodes, which can be confirmed by the average transmittance in 400-800 $\mathrm{nm}$ wavelength range in Table 1 and Table S1. For instance, the highest average value (89.28\%) of $\mathrm{Ag} \mathrm{OMO}$ electrodes with $9.0 \mathrm{~nm} \mathrm{Ag}$ is much lower than that of $\mathrm{Ag}_{(\mathrm{O})}$ OMO electrode (93.67\%) with $7.5 \mathrm{~nm} \mathrm{Ag}(\mathrm{O})$. Figure 4c shows that the sheet resistances varies with the $\mathrm{Ag}$ and $\mathrm{Ag}_{(\mathrm{O})}$ thickness; from the results, it can be seen that the sheet resistance of the $\mathrm{ZnO} / \mathrm{Ag} / \mathrm{ZnO}$ electrode decreased with the increase of Ag thickness, the slops slowed down and $\mathrm{ZnO} / 9.0-\mathrm{nm} \mathrm{Ag} / \mathrm{ZnO}$ electrode reached below $10 \Omega \mathrm{sq}^{-1}$. Although the sheet resistances of OMO electrodes with various $\mathrm{Ag}_{(\mathrm{O})}$ thickness change a little, the values are around $10 \Omega \mathrm{sq}^{-1}$ that promise a good electric property. The optimal optoelectrical properties of the $\mathrm{Ag}$ and $\mathrm{Ag}(\mathrm{O})$ OMO TCE at metallic layer thickness of $9.0 \mathrm{~nm}$ surely exceed that of amorphous ITO film electrode, which are usually available by room temperature sputtering processes on heat-sensitive PET substrates, exhibiting about $85 \%$ at about $30 \Omega \mathrm{sq}^{-1}$. The FE-SEM images in Figure $4 \mathrm{~d}-\mathrm{f}$ indicated that such optoelectrical properties were attributed to the formation of a completely continuous film geometry at the thickness. It seems that the Ag thickness of $9.0 \mathrm{~nm}$ other than $7.5 \mathrm{~nm}$ is the minimum thickness for forming such a continuous film by completely filling holes, which surely improves electron transport [52]. However, the small amount of oxygen incorporation is good for the construction of continuous thin $\mathrm{Ag}_{(\mathrm{O})}$ layer on $\mathrm{ZnO}$ layer, and the continuous film can be formed in a lower $\mathrm{Ag}_{(\mathrm{O})}$ thickness of $7.5 \mathrm{~nm}$. Even with same metallic thickness, oxygen incorporation can induce a more homogenous layer with small domain size, which causes smaller light loss and better transmittance [5].

The high transmittance and low sheet resistance promise good photovoltaic performances for flexible PSCs. To characterize the performance of OMO electrodes, flexible PSCs devices were fabricated and corresponding I-V and EQE measurements were characterized. The photovoltaic parameters of devices with 6.0, 7.5, 9.0, 12, and 15-nm thick $\mathrm{Ag}_{(\mathrm{O})}$ layers are demonstrated in Table 1, and the corresponding I-V curves of devices are shown in Figure 5a. The photovoltaic parameters of devices with 6.0, 7.5, 9.0, 10.5, and 13-nm thick Ag layers are demonstrated in Table S1, and the corresponding $\mathrm{I}-\mathrm{V}$ curves of devices are shown in Figure S1. The photovoltaic performances of $\mathrm{ZnO} / \mathrm{Ag}_{(\mathrm{O})} / \mathrm{ZnO} \mathrm{OMO}$ electrodes are obvious better than that of $\mathrm{ZnO} / \mathrm{Ag} / \mathrm{ZnO}$ OMO electrodes, which can be ascribed to better optical and electric properties demonstrated above. Carefully checking the results, it can be seen that the optimized $\operatorname{Ag}_{(\mathrm{O})}$ thickness is $7.5 \mathrm{~nm}$, with which the related devices exhibited the highest average PCE of $7.79 \%$, with relatively high average short current density (Jsc) of $17.12 \mathrm{~mA} \mathrm{~cm}^{-2}$ and highest average fill factor (FF) of $59.96 \%$, because of the relatively high total transmittance and low series resistance. Besides, the series resistance value reflects internal resistance of devices, the lower value indicated better junction contact and lower self-exploitation. Therefore, from Table 1 , it can be seen that the values of FF are in accordance with that series resistances, which means lower series resistance promises better devices structure. The devices with 6.0 and $9.0 \mathrm{~nm} \mathrm{Ag}(\mathrm{O})$ layers showed good photovoltaic performances too. Devices with $6.0 \mathrm{~nm} \mathrm{Ag}(\mathrm{O})$ layer exhibited an average PCE of 7.65\%, with highest average $J S C$ of $17.62 \mathrm{~mA} \mathrm{~cm}^{-2}$, because of the highest total transmittance. For devices with $\mathrm{Ag}_{(\mathrm{O})}$ layers more than $9.0 \mathrm{~nm}$, i.e., 12 and $15 \mathrm{~nm}$, the photovoltaic performances decrease greatly, mainly due to the greatly decreased photocurrent, which are induced by the reduced total transmittance value. The photovoltaic performances can be verified by the EQE measurement, for instance, by calculating EQE curve area, the calculated Jsc can be obtained $[46,53,54]$. Figure 5b shows the EQE curves of devices with various $\mathrm{Ag}_{(\mathrm{O})}$ thickness, and from the result, it can be seen that the device with 
$6.0 \mathrm{~nm} \mathrm{Ag}(O)$ layer shows highest EQE value, the calculated $J s c$ is $17.45 \mathrm{~mA} \mathrm{~cm}^{-2}$, which in accordance with that of value obtain by $I-V$ measurement. In addition, as Figure $5 b$ and Table 1 showed, the EQE values and calculated Jsc decrease with the increasing $\mathrm{Ag}_{(\mathrm{O})}$ thickness, which is in accordance with the changes of total transmittance. To investigate the photovoltaic performances of $\mathrm{Ag}_{(\mathrm{O})}$-based $\mathrm{OMO}$ electrode, PET/ITO $(120 \mathrm{~nm}) / \mathrm{ZnO}(40 \mathrm{~nm})$ electrodes were prepared and corresponding devices were fabricated, as the photovoltaic parameters illustrated in Table 1. Carefully checking the photovoltaic parameters, it is found that the greatly enhanced PCE of OMO devices are mainly caused by the enhanced $J s c$ and FF, with average $J s c$ increasing from 13.70 to $14.56 \mathrm{~mA} \mathrm{~cm}^{-2}$, improved by $6.27 \%$ and with average FF increasing from $55.13 \%$ to $56.70 \%$, improved by $2.84 \%$. Considering that both of the two electrodes contain relatively thick $\mathrm{ZnO}$ as top layer, the work function of $\mathrm{Ag}$ and ITO are well modified to form good interface contacts. Therefore, the slightly enhanced FF might be caused by the improved sheet resistance. It is more reasonable to believe that the greatly enhanced Jsc is caused by the microresonant cavity effects, with the evidence that lower average total transmittance and higher Jsc is present in OMO devices compared with that of ITO devices.

(a)

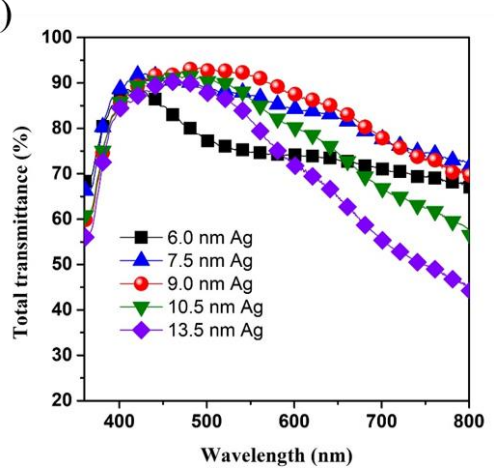

(c)

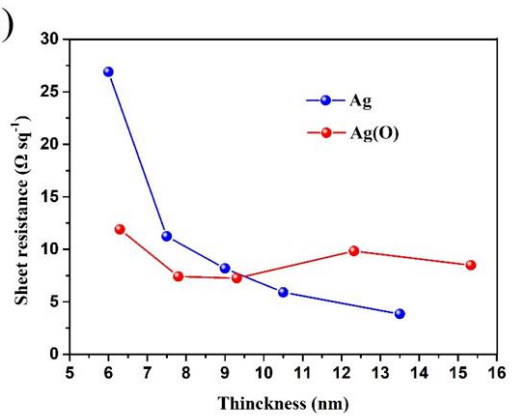

(e)

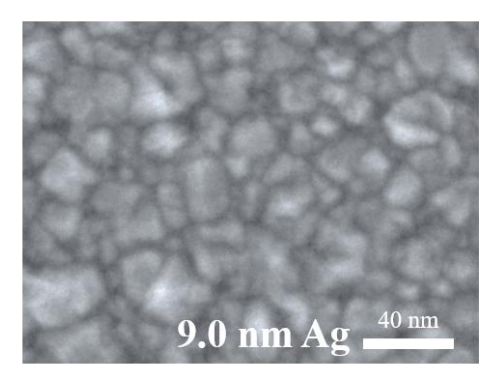

(b)

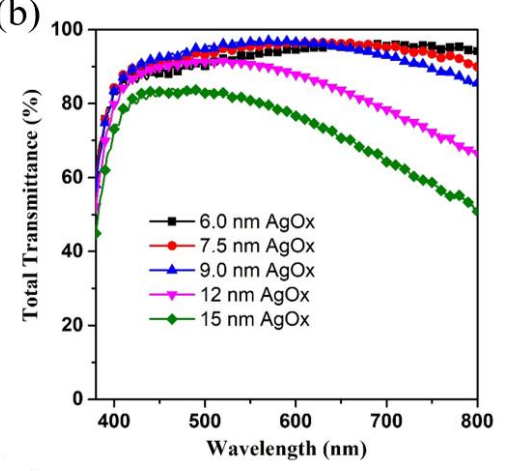

(d)

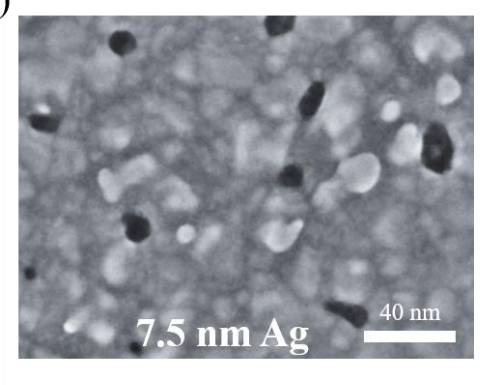

(f)

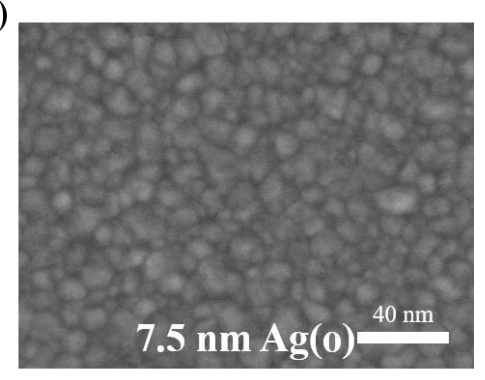

Figure 4. (a) Total transmittance of PET substrate with $\mathrm{ZnO} / \mathrm{Ag} / \mathrm{ZnO}$ OMO electrode for various $\mathrm{Ag}$ thicknesses, 6.0, 7.5, 9.0, 10.5, and $13.5 \mathrm{~nm}$; (b) Total transmittance of PET substrate with $\mathrm{ZnO} / \mathrm{Ag}_{(\mathrm{O})} / \mathrm{ZnO}$ OMO electrode for various $\mathrm{Ag}_{(\mathrm{O})}$ thicknesses, 6.0, 7.5, 9.0,12, and $15 \mathrm{~nm}$; (c) sheet resistance variation as a function of different metallic layer thickness; and SEM images of $\mathrm{Ag}(7.5 \mathrm{~nm})(\mathbf{d}), \mathrm{Ag}(9.0 \mathrm{~nm})(\mathbf{e})$, and $\mathrm{Ag}_{(\mathrm{O})}(7.5 \mathrm{~nm})(\mathbf{f})$. 
Table 1. $\mathrm{Ag}_{(\mathrm{O})}$ thickness optimizing of PET/ZnO/Ag $(\mathrm{O})(6.0,7.5,9.0,12$, and $15 \mathrm{~nm}) / \mathrm{ZnO}$ substrates.

\begin{tabular}{|c|c|c|c|c|c|c|c|c|}
\hline TE Type & $\begin{array}{c}\operatorname{Ag}(\mathrm{O}) \\
\text { Thickness (nm) }\end{array}$ & $\begin{array}{l}\text { Average T (\%) } \\
\text { in } 400-800 \mathrm{~nm}\end{array}$ & Voc (V) & $J s c\left(\mathrm{~mA} \mathrm{~cm}^{-2}\right)$ & FF (\%) & PCE (\%) & $\begin{array}{l}\text { Calculated } J s c \text { from } \\
\text { EQE }\left(\mathrm{mA} \mathrm{cm}^{-2}\right)\end{array}$ & $\operatorname{Rs}\left(\Omega \mathrm{cm}^{2}\right)$ \\
\hline $\mathrm{ZnO} / \mathrm{Ag}_{(\mathrm{O})} / \mathrm{ZnO}$ & 6.0 & 92.90 & $0.77 \pm 0.01$ & $17.62 \pm 0.25$ & $56.42 \pm 0.56$ & $7.65 \pm 0.11$ & 17.45 & 6.57 \\
\hline $\mathrm{ZnO} / \mathrm{Ag}_{(\mathrm{O})} / \mathrm{ZnO}$ & 7.5 & 93.67 & $0.76 \pm 0.01$ & $17.12 \pm 0.32$ & $59.96 \pm 0.42$ & $7.79 \pm 0.13$ & 17.04 & 3.07 \\
\hline $\mathrm{ZnO} / \mathrm{Ag}_{(\mathrm{O})} / \mathrm{ZnO}$ & 9.0 & 92.96 & $0.76 \pm 0.01$ & $16.64 \pm 0.37$ & $58.49 \pm 0.63$ & $7.40 \pm 0.16$ & 16.26 & 3.58 \\
\hline $\mathrm{ZnO} / \mathrm{Ag}_{(\mathrm{O})} / \mathrm{ZnO}$ & 12 & 83.60 & $0.76 \pm 0.01$ & $14.56 \pm 0.42$ & $56.70 \pm 0.78$ & $6.27 \pm 0.21$ & 13.59 & 5.79 \\
\hline $\mathrm{ZnO} / \mathrm{Ag}_{(\mathrm{O})} / \mathrm{ZnO}$ & 15 & 72.79 & $0.77 \pm 0.01$ & $12.07 \pm 0.39$ & $50.34 \pm 0.69$ & $4.65 \pm 0.19$ & 11.51 & 10.11 \\
\hline ITO/ZnO & 0 & 85.66 & $0.77 \pm 0.01$ & $13.70 \pm 0.22$ & $55.13 \pm 0.53$ & $5.90 \pm 0.24$ & & 9.24 \\
\hline
\end{tabular}

The average photovoltaic values were obtained from 10 devices. 

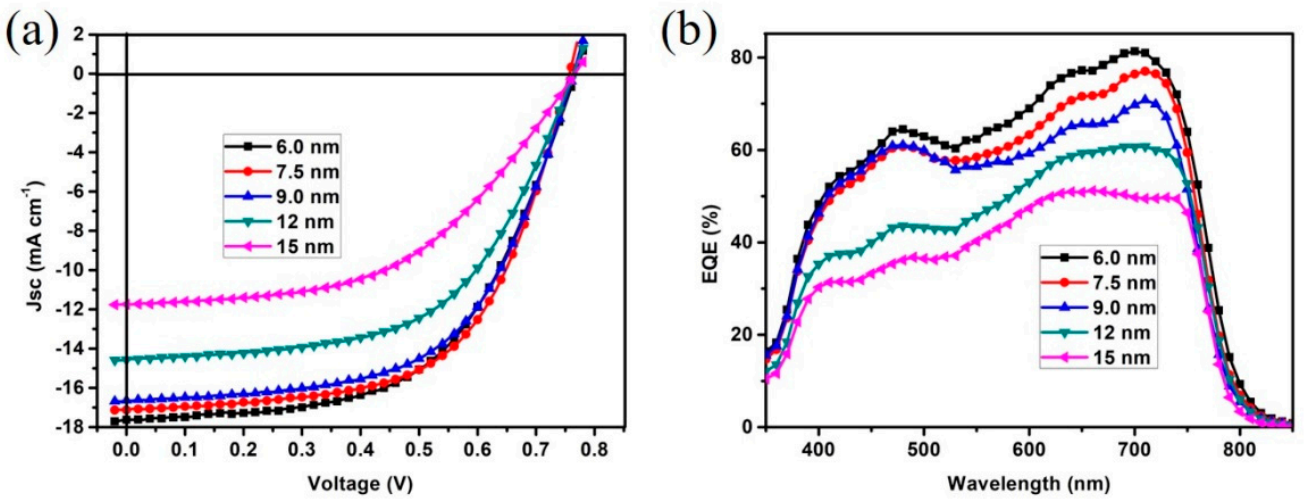

Figure 5. (a) $\mathrm{I}-\mathrm{V}$ curves of devices with $\mathrm{ZnO} / \mathrm{Ag}_{(\mathrm{O})} / \mathrm{ZnO}$ electrodes for different $\mathrm{Ag}(\mathrm{O})$ thickness, (b) corresponding EQE spectra of devices with different $\mathrm{Ag}_{(\mathrm{O})}$ thickness.

To further increase the photovoltaic performance of $\mathrm{ZnO} / \mathrm{Ag}_{(\mathrm{O})} / \mathrm{ZnO}$-based flexible PSCs, $\mathrm{Ag} @ \mathrm{SiO}_{2}-\mathrm{NPs}$ were introduced to the PTB7-Th:PC ${ }_{71} \mathrm{BM}$ blend active layers to utilize the plasmonic effects of metallic nanoparticles, and the incorporation concentration of $\mathrm{Ag} @ \mathrm{SiO}_{2}-\mathrm{NPs}$ was optimized by constructing devices with various concentrations, as Table 2 illustrated detailed photovoltaic parameters and Figure 6a showed the corresponding I-V curves. From the results, it can be seen that the optimized $\mathrm{Ag} @ \mathrm{SiO}_{2}-\mathrm{NPs}$ concentration is $1.0 \mathrm{wt} \%$; with the optimized concentration, the average PCE can be as high as $8.04 \%$, with highest average $J s c$ as $17.98 \mathrm{~mA} \mathrm{~cm}^{-2}$ and relatively high average FF of $58.40 \%$. Compared with the PCE of ITO devices shown in Table 1, the PCE of devices with $1.0 \mathrm{wt} \%$ $\mathrm{Ag} @ \mathrm{SiO}_{2}-\mathrm{NPs}$ increased by $36.27 \%$ because of the dual effects, plasmonic effect and microresonant cavity effect. Similar enhancements can also be achieved with $\mathrm{ZnO} / \mathrm{Ag} / \mathrm{ZnO}$ OMO electrodes, as results shown in Table S2 and Figure S2. Besides, in Table 2, with higher concentrations, the Jsc and FF of devices are relatively lower than that of optimized devices, which may be caused by the destruction of the internetwork of active layer by the large aggregations due to the high NPs incorporation, which has been illustrated in detail in our previous papers. The destroyed nanostructure can be confirmed by the Rs values, as with lower concentrations, the Rs value is higher than that of devices with higher concentrations, which indicates that as the concentration increases, the internal series increases and the working efficiency decreases. In addition, with lower concentration, i.e., $0.5 \mathrm{wt} \%$, Jsc decreases while the FF value remains high, as the average value of $58.49 \%$. There is no difference for Voc values of devices with various $\mathrm{Ag} @ \mathrm{SiO}_{2}-\mathrm{NPs}$ concentrations, which indicates that the incorporation of $\mathrm{Ag} @ \mathrm{SiO}_{2}-\mathrm{NPs}$ causes no electric changes, because of the encapsulation of metallic nanoparticles by dielectric material $\left(\mathrm{SiO}_{2}\right)$. Our previous research [48] have proved that without $\mathrm{SiO}_{2}$ encapsulation, the bared Ag nanoparticle will induce great decrease of photovoltaic performances, with greatly decreased $V o c, J s c$, and $F F$ values. This phenomenon is caused by excitons quenching, which is induced by the incorporated Ag nanoparticles acting as the recombination center to quench the excitons. The dielectric material $\mathrm{SiO}_{2}$ encapsulation can perfectly prevent the excitons quenching without causing electric changes, as utilizing their plasmonic effects during main effective charge separation working mechanism. However, it is unavoidable that the incorporation of $\mathrm{Ag} @ \mathrm{SiO}_{2}-\mathrm{NPs}$ slightly affects the interpenetrating nanostructure of active layer, which may cause the changes of FF and Rs. Figure $6 \mathrm{~b}$ shows the EQE spectra of devices with or without optimized $\mathrm{Ag} @ \mathrm{SiO}_{2}-\mathrm{NPs}$ concentrations. As a result, with $\mathrm{Ag} @ \mathrm{SiO}_{2}-\mathrm{NPs}$, the EQE spectrum of device shows enhanced values in the wavelength range of $400-500 \mathrm{~nm}$, which is in accordance with the LSPR wavelength range. Therefore, it is reasonable to believe that the enhancements are caused by the LSPR effect of nanoparticle. In addition, considering the relatively large $\mathrm{Ag} @ \mathrm{SiO}_{2}-\mathrm{NPs}$ size, there are the light scattering effect of NPs, which is good for the enlarging of the light paths, thus good for the light absorption. 
Table 2. Ag@SiO 2 concentration optimizing in active layer on $\mathrm{PET} / \mathrm{ZnO} / \mathrm{Ag}(\mathrm{O})(7.5 \mathrm{~nm}) / \mathrm{ZnO}$ substrates.

\begin{tabular}{cccccc}
\hline $\mathbf{A g} @ \mathrm{SiO}_{\mathbf{2}}$ conc. & Voc $(\mathbf{V})$ & Jsc $\left(\mathbf{m A ~ c m} \mathbf{~ c m}^{-2}\right)$ & FF (\%) & PCE (\%) & Rs $\left(\boldsymbol{\Omega} \mathbf{~ c m}^{\mathbf{2}}\right)$ \\
\hline $2.0 \mathrm{wt} \%$ & $0.76 \pm 0.01$ & $17.25 \pm 0.24$ & $55.41 \pm 0.71$ & $7.26 \pm 0.19$ & 9.67 \\
$1.5 \mathrm{wt} \%$ & $0.76 \pm 0.01$ & $17.39 \pm 0.36$ & $56.88 \pm 0.84$ & $7.51 \pm 0.31$ & 6.34 \\
$1.0 \mathrm{wt} \%$ & $0.77 \pm 0.01$ & $17.98 \pm 0.28$ & $58.40 \pm 0.52$ & $8.04 \pm 0.21$ & 3.27 \\
$0.5 \mathrm{wt} \%$ & $0.76 \pm 0.01$ & $17.22 \pm 0.29$ & $58.49 \pm 0.44$ & $7.69 \pm 0.16$ & 4.06 \\
\hline
\end{tabular}

The average photovoltaic values were obtained from 10 devices.
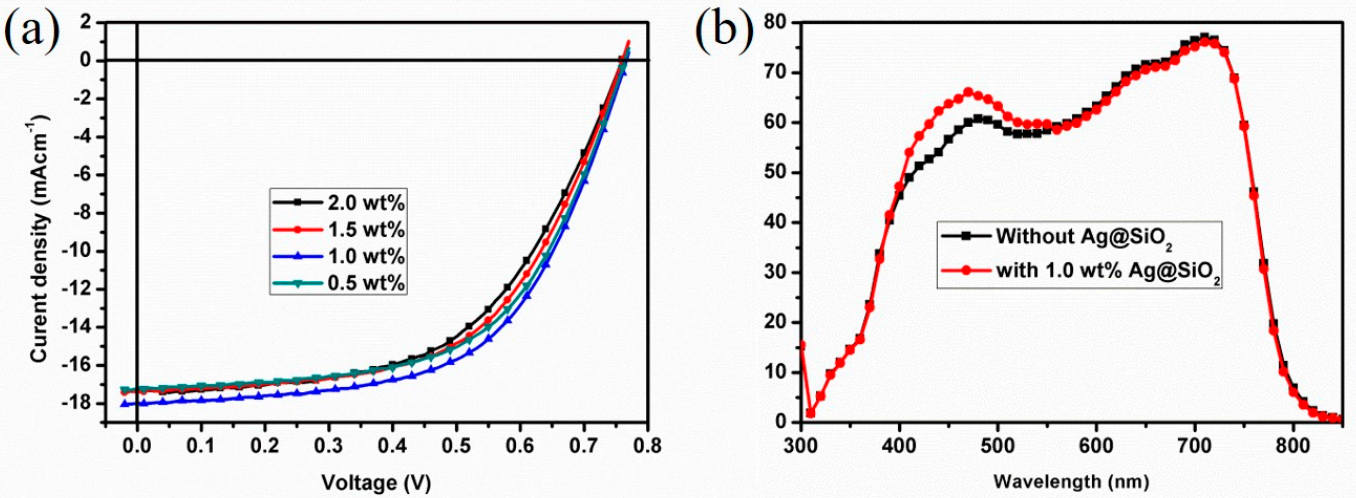

Figure 6. (a) I-V curves of devices with different weight percent $\mathrm{Ag} @ \mathrm{SiO}_{2}-\mathrm{NPs}$ incorporation, (b) EQE curves of device with optimized $\mathrm{Ag} @ \mathrm{SiO}_{2}-\mathrm{NPs}$ incorporation and that of the reference device.

It is difficult to demonstrate the incorporation of $\mathrm{Ag} @ \mathrm{SiO}_{2}-\mathrm{NPs}$ caused the enhanced light absorption directly by one characterization. However, it can be proved by the photoluminescence (PL) measurement of PTB7-Th film with $1 \mathrm{wt} \% \mathrm{Ag@SiO}{ }_{2}-\mathrm{NPs}$ and pure PTB7-Th film [40,54]. The reasons that PL measurement verifies the light enhancement can be illustrated by Figure 7a. As seen, PTB7-Th absorbs photons-induced electrons excited to the excited states, and go to the relatively stable the first excited state (LUMO). Most of electrons on first excited state of donor material (PTB7-Th) will transfer to the first excited state of acceptor material $\left(\mathrm{PC}_{71} \mathrm{BM}\right)$ if existed, and there is photovoltaic process. Without acceptor materials, electrons on first excited state of donor material (PTB7-Th) will go back to the ground state by the energy release of luminescence or heat. Therefore, it is reasonable to believe that the PL intensity is proportional to the absorption of light and the PL measurement can be used to verify the enhanced light. To guarantee the reliability of the PL results, the concentration of donor polymer, solvent, and spin coating speed were fixed; as a result, the thickness of pure PTB7-Th film and

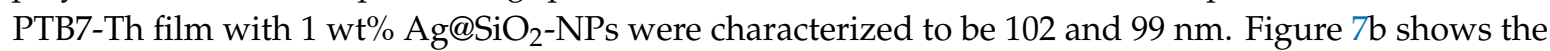
PL intensity results of pure PTB7-Th film and PTB7-Th film with $1 \mathrm{wt} \% \mathrm{Ag} @ \mathrm{SiO}_{2}-\mathrm{NPs}$; the PL intensity

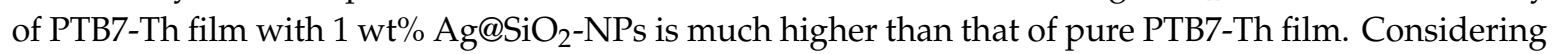
the similar film thickness, the enhanced PL intensity is caused by enhanced light absorption. Therefore, it can be verified that the incorporation of $\mathrm{Ag} @ \mathrm{SiO}_{2}-\mathrm{NPs}$ indeed cause the enhanced light absorption of active layers, by the LSPR effect and light-scattering effect. 
(a)

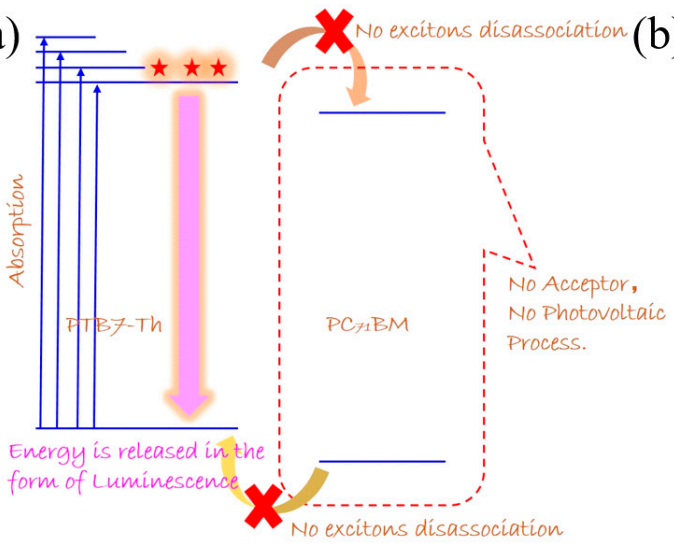

(b)

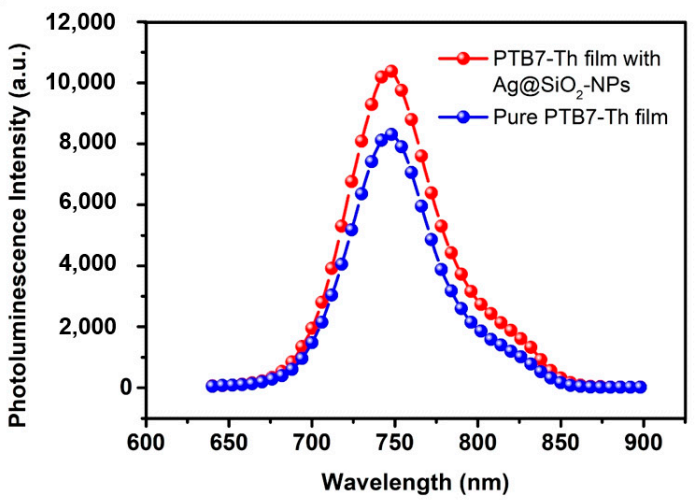

Figure 7. (a) Schematic diagram of the luminescence process without the existence of $\mathrm{PC}_{71} \mathrm{BM}$ and (b) photoluminescence spectra of pure PTB7-Th film and PTB7-Th film with Ag@SiO $2-\mathrm{NPs}$; excitation wavelength was $612 \mathrm{~nm}$.

Rollability is an important property for flexible PSCs along with the photovoltaic performances. In order to evaluate the rollability of flexible PSCs with $\mathrm{ZnO} / \mathrm{Ag}_{(\mathrm{O})} / \mathrm{ZnO}$ OMO electrodes, the bending tests were implemented by bending the PSC devices on a cylinder with a diameter of $7.5 \mathrm{~mm}$, as schematically illustrated in Figure 8a [52]. The PCE value was recorded after 10, 25, 50, 75, and 100 times bending, as shown in Figure $8 \mathrm{~b}$. The flexible PSC using a $\mathrm{ZnO} / \mathrm{Ag}_{(\mathrm{O})} / \mathrm{ZnO}$ electrode exhibited excellent rollability by maintaining over $90 \%$ performance after 100 times bending. However, the same device using an ITO electrode exhibited much poorer rollability. After 10 times bending, the normalized PCE decreased greatly.
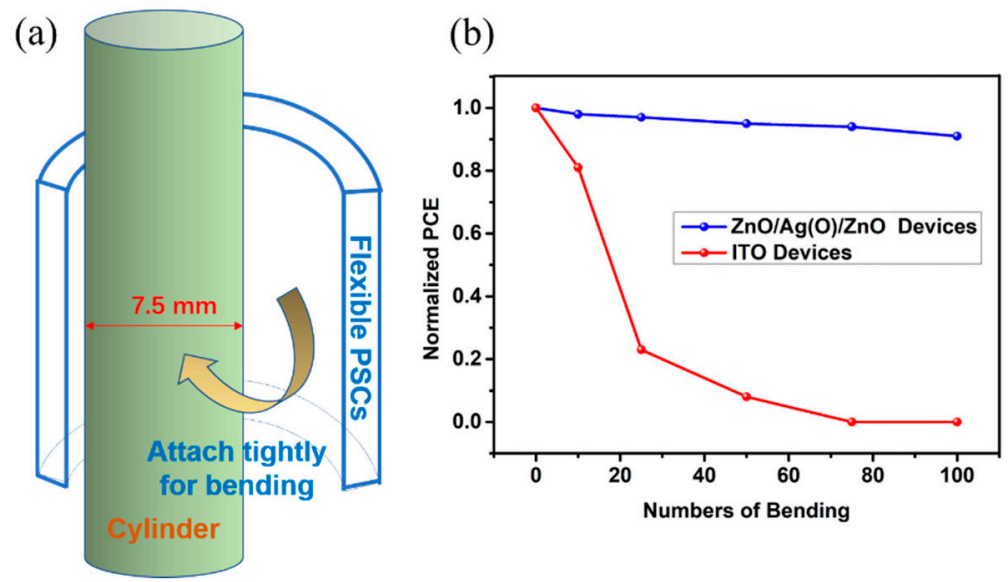

Figure 8. (a) Schematic diagram of bending test and (b) changes in the normalized PCE of PSC devices utilizing $\mathrm{ZnO} / \mathrm{Ag}_{(\mathrm{O})} / \mathrm{ZnO}$ and $\mathrm{ITO}$ electrodes as a function of number of bending.

\section{Conclusions}

High transmittance and low sheet resistance OMO electrodes were implemented as the electrode materials on flexible PET substrates. By small amount of oxygen, continuous metallic film can be formed with lower thickness in $\mathrm{Ag}_{(\mathrm{O})} \mathrm{OMO}$ electrodes other than $\mathrm{Ag}$ OMO electrodes, which result in much higher average total transmittance and lower sheet resistance. As a result, with $7.5 \mathrm{~nm} \mathrm{Ag}(\mathrm{O})$, the devices can obtain high Jsc and high FF, thus high PCE. With OMO electrode and back metal electrode, microresonance cavity effect plays an important part in trapping light between OMO and back electrode, which greatly increases the light path. To further enhance the photovoltaic performance of flexible PSCs, $\mathrm{Ag} @ \mathrm{SiO}_{2}-\mathrm{NPs}$ were incorporated to active layer to utilize the plasmonic effect. With optimized concentration of $\mathrm{Ag} @ \mathrm{SiO}_{2}-\mathrm{NPs}$, the average PCE can be enhanced by $36.27 \%-8.04 \%$, with 
enhanced Jsc value of $17.98 \mathrm{~mA} \mathrm{~cm}^{-2}$. The enhanced EQE wavelength range is in accordance with that of LSPR wavelength range indicating that enhancement is induced by the LSPR effect. The PL measurement verified that the incorporation of $\mathrm{Ag} @ \mathrm{SiO}_{2}-\mathrm{NPs}$ indeed causes the enhanced light absorption. Besides, the flexible devices with OMO electrodes exhibit much better rollability, compared with that of ITO devices. All in all, the incorporation of Ag@SiO $2-\mathrm{NPs}$ to OMO-based flexible PSCs achieved good photovoltaic performances, induced by the plasmonic and microresonance cavity effects, which can be utilized in the future commercialization of flexible PSCs.

Supplementary Materials: The following are available online at http://www.mdpi.com/2079-4991/10/5/944/s1, Figure S1: (a) I-V curves and corresponding EQE spectra of PSCs using ZnO/Ag/ZnO electrodes with different Ag thicknesses, Figure S2. (a) I-V curves of PSC devices using different concentrations of $\mathrm{Ag}-\mathrm{SiO}_{2}-\mathrm{NPs}_{\text {incorporated }}$ in the photoactive layer, (b) Comparison of EQE spectra of a PSC device applying the optimized incorporation of NPs and a NP-free PSC device, Table S1: Photovoltaic performances of PSCs fabricated using PET/ZnO/Ag/ZnO substrates with different Ag thicknesses, Table S2: Changes in photovoltaic performances of flexible PSCs using a $\mathrm{ZnO} / 7.5-\mathrm{nm} / \mathrm{ZnO} \mathrm{TCE}$ as a function of the concentration of $\mathrm{Ag}-\mathrm{SiO}_{2}-\mathrm{NPs}$.

Author Contributions: W.S. investigation, and writing the manuscript; G.Z., investigation the electrodes; X.Z., wring the manuscript; F.B., investigation; J.Y., supervision and editing; J.T., funding acquisition. All authors have read and agreed to the published version of the manuscript.

Funding: (1) the Natural Scientific Foundation of China (Grant No. 51,273,096 and 51,473,082), (2) State Key Project of International Cooperation Research (2017YFE0108300 and 2016YFE0110800), (3) Shandong Double-Hundred Project, (4) the Program for Introducing Talents of Discipline to Universities ("111" plan), (5) Qingdao Basic Research on Application of Science and Technology Plan (19-6-2-82-cg), (6) The National One-Thousand Foreign Expert Program (Grant No. WQ20123700111), (7) The 1st Level Discipline Program of Shandong Province of China, and (8) Research Start-Up Funds of Qingdao University. J.Y. and G.Z. were supported by the Fundamental Research Program of the Korea Institute of Materials Science (PNK6100).

Acknowledgments: Thanks to Pinghui Wu in Zhejiang University for FDTD simulation.

Conflicts of Interest: The authors declare no conflicts of interest.

\section{References}

1. Fan, B.; Zhang, D.; Li, M.; Zhong, W.; Zeng, Z.; Ying, L.; Huang, F.; Cao, Y. Achieving over 16\% efficiency for single-junction organic solar cells. Sci. China Chem. 2019, 62, 746-752. [CrossRef]

2. Meng, L.; Yamin, Z.; Xiangjian, W.; Chenxi, L.; Xin, Z.; Yanbo, W.; Xin, K.; Zuo, X.; Liming, D.; Ruoxi, X. Organic and solution-processed tandem solar cells with 17.3\% efficiency. Science 2018, 361, 1094-1099. [CrossRef] [PubMed]

3. Yuan, J.; Zhang, Y.; Zhou, L.; Zhang, G.; Yip, H.-L.; Lau, T.-K.; Lu, X.; Zhu, C.; Peng, H.; Johnson, P.A.; et al. Single-Junction Organic Solar Cell with over 15\% Efficiency Using Fused-Ring Acceptor with Electron-Deficient Core. Joule 2019, 3, 1140-1151. [CrossRef]

4. An, Q.; Zhang, F.; Zhang, J.; Tang, W.; Deng, Z.; Hu, B. Versatile ternary organic solar cells: A critical review. Energy Environ. Sci. 2016, 9, 281-322. [CrossRef]

5. Yun, J. Ultrathin Metal films for Transparent Electrodes of Flexible Optoelectronic Devices. Adv. Funct. Mater. 2017, 27, 1606641. [CrossRef]

6. Lee, J.; Lee, S.M.; Chen, S.; Kumari, T.; Kang, S.H.; Cho, Y.; Yang, C. Organic Photovoltaics with Multiple Donor-Acceptor Pairs. Adv. Mater. 2018, 31, 1804762. [CrossRef]

7. Guo, W.; Xu, Z.; Zhang, F.; Xie, S.; Xu, H.; Liu, X.Y. Recent Development of Transparent Conducting Oxide-Free Flexible Thin-Film Solar Cells. Adv. Funct. Mater. 2016, 26, 8855-8884. [CrossRef]

8. Zilberberg, K.; Riedl, T. Metal-nanostructures-A modern and powerful platform to create transparent electrodes for thin-film photovoltaics. J. Mater. Chem. A 2016, 4, 14481-14508. [CrossRef]

9. Chueh, C.C.; Crump, M.; Jen, A.K.Y. Optical Enhancement via Electrode Designs for High-Performance Polymer Solar Cells. Adv. Funct. Mater. 2016, 26, 321-340. [CrossRef]

10. Kaltenbrunner, M.; White, M.S.; Glowacki, E.D.; Sekitani, T.; Someya, T.; Sariciftci, N.S.; Bauer, S. Ultrathin and lightweight organic solar cells with high flexibility. Nat. Commun. 2012, 3, 7. [CrossRef] [PubMed]

11. Li, L.; Wu, Z.; Yuan, S.; Zhang, X.-B. Advances and challenges for flexible energy storage and conversion devices and systems. Energy Environ. Sci. 2014, 7, 2101-2122. [CrossRef] 
12. Kaltenbrunner, M.; Sekitani, T.; Reeder, J.; Yokota, T.; Kuribara, K.; Tokuhara, T.; Drack, M.; Schwoediauer, R.; Graz, I.; Bauer-Gogonea, S.; et al. An ultra-lightweight design for imperceptible plastic electronics. Nature 2013, 499, 458. [CrossRef] [PubMed]

13. Bernardi, M.; Palummo, M.; Grossman, J.C. Extraordinary Sunlight Absorption and One Nanometer Thick Photovoltaics Using Two-Dimensional Monolayer Materials. Nano Lett. 2013, 13, 3664-3670. [CrossRef] [PubMed]

14. Jeong, E.; Zhao, G.; Song, M.; Yu, S.M.; Rha, J.; Shin, J.; Cho, Y.-R.; Yun, J. Simultaneous improvements in self-cleaning and light-trapping abilities of polymer substrates for flexible organic solar cells. J. Mater. Chem. A 2018, 6, 2379-2387. [CrossRef]

15. Zhao, G.; Kim, S.M.; Lee, S.-G.; Bae, T.-S.; Mun, C.; Lee, S.; Yu, H.; Lee, G.-H.; Lee, H.-S.; Song, M.; et al. Bendable Solar Cells from Stable, Flexible, and Transparent Conducting Electrodes Fabricated Using a Nitrogen-Doped Ultrathin Copper Film. Adv. Funct. Mater. 2016, 26, 4180-4191. [CrossRef]

16. Wang, W.; Song, M.; Bae, T.-S.; Park, Y.H.; Kang, Y.-C.; Lee, S.-G.; Kim, S.-Y.; Kim, D.H.; Lee, S.; Min, G.; et al. Transparent Ultrathin Oxygen-Doped Silver Electrodes for Flexible Organic Solar Cells. Adv. Funct. Mater. 2014, 24, 1551-1561. [CrossRef]

17. Behrendt, A.; Friedenberger, C.; Gahlmann, T.; Trost, S.; Becker, T.; Zilberberg, K.; Polywka, A.; Görrn, P.; Riedl, T. Highly Robust Transparent and Conductive Gas Diffusion Barriers Based on Tin Oxide. Adv. Mater. 2015, 27, 5961. [CrossRef]

18. Yue, B.L.; Jia, D.; Tang, J.; Zhang, A.; Liu, F.; Chen, T.; Barrow, C.; Yang, W.; Liu, J. Improving the rate capability of ultrathin $\mathrm{NiCo}-\mathrm{LDH}$ nanoflakes and $\mathrm{FeOOH}$ nanosheets on surface electrochemically modified graphite fibers for flexible asymmetric supercapacitors. J. Colloid Interface Sci. 2020, 560, 237-246. [CrossRef]

19. Guo, J.; Tang, J.; Wang, J.; Mao, S.; Li, H.; Wang, Y.; Liu, J.; Wang, Y.; Huang, L.; Kipper, M.J.; et al. Europium(III)-induced water-soluble nano-aggregates of hyaluronic acid and chitosan: Structure and fluorescence. MRS Commun. 2018, 8, 1224-1229. [CrossRef]

20. Xue, J.; Liu, J.; Mao, S.; Wang, Y.; Shen, W.; Wang, W.; Huang, L.; Li, H.; Tang, J. Recent progress in synthetic methods and applications in solar cells of Ag2S quantum dots. Mater. Res. Bull. 2018, 106, 113-123. [CrossRef]

21. Yan, P.; Tang, J.; Zhang, Y.; Shen, W.; Wang, Y.; Hou, L.; Tian, R.; Wang, Y.; Li, H.; Huang, L.; et al. SPR-enhanced fluorescence and protein-improved blood compatibility of quadruple core/shell nanostructure of Ag@SiO2@Eu3+(tta)(3)Phen@Protein. Micro Nano Lett. 2018, 13, 1447-1452. [CrossRef]

22. Yun, J.; Wang, W.; Bae, T.S.; Park, Y.H.; Kang, Y.C.; Kim, D.H.; Lee, S.; Lee, G.H.; Song, M.; Kang, J.W. Preparation of flexible organic solar cells with highly conductive and transparent metal-oxide multilayer electrodes based on silver oxide. ACS Appl. Mater. Interfaces 2013, 5, 9933-9941. [CrossRef] [PubMed]

23. Seo, K.-W.; Lee, J.; Jo, J.; Cho, C.; Lee, J.-Y. Highly Efficient (>10\%) Flexible Organic Solar Cells on PEDOT-Free and ITO-Free Transparent Electrodes. Adv. Mater. 2019, 31, 1902447. [CrossRef] [PubMed]

24. Lu, H.; Ren, X.; Ouyang, D.; Choy, W.C.H. Emerging Novel Metal Electrodes for Photovoltaic Applications. Small 2018, 14, 1703140. [CrossRef] [PubMed]

25. Kim, S.; Sanyoto, B.; Park, W.-T.; Kim, S.; Mandal, S.; Lim, J.-C.; Noh, Y.-Y.; Kim, J.-H. Purification of PEDOT: PSS by Ultrafiltration for Highly Conductive Transparent Electrode of All-Printed Organic Devices. Adv. Mater. 2016, 28, 10149-10154. [CrossRef] [PubMed]

26. Kan, Z.; Wang, Z.; Firdaus, Y.; Babics, M.; Alshareef, H.N.; Beaujuge, P.M. Atomic-layer-deposited AZO outperforms ITO in high-efficiency polymer solar cells. J. Mater. Chem. A 2018, 6, 10176-10183. [CrossRef]

27. Han, Y.; Chen, X.; Wei, J.; Ji, G.; Wang, C.; Zhao, W.; Lai, J.; Zha, W.; Li, Z.; Yan, L.; et al. Efficiency above $12 \%$ for $1 \mathrm{~cm}(2)$ Flexible Organic Solar Cells with Ag/Cu Grid Transparent Conducting Electrode. Adv. Sci. 2019, 6, 1901490. [CrossRef]

28. Chu, J.H.; Lee, D.H.; Jo, J.; Kim, S.Y.; Yoo, J.-W.; Kwon, S.-Y. Highly Conductive and Environmentally Stable Organic Transparent Electrodes Laminated with Graphene. Adv. Funct. Mater. 2016, 26, 7234-7243. [CrossRef]

29. Zhang, C.; Zhao, D.; Gu, D.; Kim, H.; Ling, T.; Wu, Y.-K.R.; Guo, L.J. An Ultrathin, Smooth, and Low-Loss Al-Doped Ag Film and Its Application as a Transparent Electrode in Organic Photovoltaics. Adv. Mater. 2014, 26, 5696-5701. [CrossRef]

30. Hutter, O.S.; Stec, H.M.; Hatton, R.A. An Indium-Free Low Work Function Window Electrode for Organic Photovoltaics Which Improves with In-Situ Oxidation. Adv. Mater. 2013, 25, 284-288. [CrossRef] 
31. Yuan, N.; Jiang, Q.; Li, J.; Tang, J. A review on non-noble metal based electrocatalysis for the oxygen evolution reaction. Arab. J. Chem. 2020, 13, 4294-4309. [CrossRef]

32. Omrani, M.K.; Fallah, H. Improving light trapping of polymer solar cell via doping a new array of triple core-shell spherical nanoparticles utilizing realistic modeling. Sol. Energy 2018, 163, 600-609. [CrossRef]

33. Ou, Q.D.; Li, Y.Q.; Tang, J.X. Light Manipulation in Organic Photovoltaics. Adv. Sci. (Weinheim) 2016, 3, 1600123. [CrossRef] [PubMed]

34. Srivastava, A.; Samajdar, D.P.; Sharma, D. Plasmonic effect of different nanoarchitectures in the efficiency enhancement of polymer based solar cells: A review. Sol. Energy 2018, 173, 905-919. [CrossRef]

35. Lee, J.; Kim, S.-Y.; Kim, C.; Kim, J.-J. Enhancement of the short circuit current in organic photovoltaic devices with microcavity structures. Appl. Phys. Lett. 2010, 97, 083306. [CrossRef]

36. Lin, H.W.; Chiu, S.W.; Lin, L.Y.; Hung, Z.Y.; Chen, Y.H.; Lin, F.; Wong, K.T. Device engineering for highly efficient top-illuminated organic solar cells with microcavity structures. Adv. Mater. 2012, 24, 2269-2272. [CrossRef] [PubMed]

37. Chen, Y.H.; Chen, C.W.; Huang, Z.Y.; Lin, W.C.; Lin, L.Y.; Lin, F.; Wong, K.T.; Lin, H.W. Microcavity-embedded, colour-tuneable, transparent organic solar cells. Adv. Mater. 2014, 26, 1129-1134. [CrossRef]

38. Yao, K.; Xin, X.-K.; Chueh, C.-C.; Chen, K.-S.; Xu, Y.-X.; Jen, A.K.Y. Enhanced Light-Harvesting by Integrating Synergetic Microcavity and Plasmonic Effects for High-Performance ITO-Free Flexible Polymer Solar Cells. Adv. Funct. Mater. 2015, 25, 567-574. [CrossRef]

39. Yao, K.; Salvador, M.; Chueh, C.-C.; Xin, X.-K.; Xu, Y.-X.; deQuilettes, D.W.; Hu, T.; Chen, Y.; Ginger, D.S.; Jen, A.K.Y. A General Route to Enhance Polymer Solar Cell Performance using Plasmonic Nanoprisms. Adv. Energy Mater. 2014, 4, 1400206-1400213. [CrossRef]

40. Kurokawa, Y.; Miyazaki, H.T. Metal-insulator-metal plasmon nanocavities: Analysis of optical properties. Phys. Rev. B 2007, 75, 035411. [CrossRef]

41. Shen, W.; Tang, J.; Ning, W.; Yao, W.; Jixian, L.; Linjun, H.; Jiuxing, W.; Yanxin, W.; Wei, W.; Renqiang, Y.; et al. The Improved Efficiency of Polymer Solar Cells by Fluorine Atoms at Ortho-Position of Alkxoyphenyl Group in Benzodithiophene (BDT) Units. Int. J. Electrochem. Sci. 2017, 12, 6676-6693. [CrossRef]

42. Chen, W.; Huang, G.; Li, X.; Li, Y.; Wang, H.; Jiang, H.; Zhao, Z.; Yu, D.; Wang, E.; Yang, R. Revealing the Position Effect of an Alkylthio Side Chain in Phenyl-Substituted Benzodithiophene-Based Donor Polymers on the Photovoltaic Performance of Non-Fullerene Organic Solar Cells. ACS Appl. Mater. Interfaces 2019, 11, 33173-33178. [CrossRef] [PubMed]

43. Zhao, G.; Wang, W.; Bae, T.S.; Lee, S.G.; Mun, C.; Lee, S.; Yu, H.; Lee, G.H.; Song, M.; Yun, J. Stable ultrathin partially oxidized copper film electrode for highly efficient flexible solar cells. Nat. Commun. 2015, 6, 8830. [CrossRef] [PubMed]

44. Wang, D.; Shen, W.; Tang, J.; Wang, Y.; Liu, J.; Wang, X.; Yang, R.; Snow, C.D.; Huang, L.; Jiao, J.; et al. Enhancing the Power Conversion Efficiency for Polymer Solar Cells by Incorporating Luminescent Nanosolid Micelles as Light Converter. ACS Appl. Energy Mater. 2018, 1, 1445-1454. [CrossRef]

45. Bu, F.; Shen, W.; Zhang, X.; Wang, Y.; Belfiore, L.A.; Tang, J. Hybrid ZnO Electron Transport Layer by Down Conversion Complexes for Dual Improvements of Photovoltaic and Stable Performances in Polymer Solar Cells. Nanomaterials 2020, 10, 80. [CrossRef] [PubMed]

46. Li, J.; Wang, Y.; Liang, Z.; Wang, N.; Tong, J.; Yang, C.; Bao, X.; Xia, Y. Enhanced Organic Photovoltaic Performance through Modulating Vertical Composition Distribution and Promoting Crystallinity of the Photoactive Layer by Diphenyl Sulfide Additives. ACS Appl. Mater. Interfaces 2019, 11, 7022-7029. [CrossRef]

47. Li, J.; Liang, Z.; Wang, Y.; Li, H.; Tong, J.; Bao, X.; Xia, Y. Enhanced efficiency of polymer solar cells through synergistic optimization of mobility and tuning donor alloys by adding high-mobility conjugated polymers. J. Mater. Chem. C 2018, 6, 11015-11022. [CrossRef]

48. Shen, W.; Tang, J.; Wang, Y.; Liu, J.; Huang, L.; Chen, W.; Yang, L.; Wang, W.; Wang, Y.; Yang, R.; et al. Strong Enhancement of Photoelectric Conversion Efficiency of Co-hybridized Polymer Solar Cell by Silver Nanoplates and Core-Shell Nanoparticles. ACS Appl. Mater. Interfaces 2017, 9, 5358-5365. [CrossRef]

49. Hedley, G.J.; Ruseckas, A.; Samuel, I.D.W. Light Harvesting for Organic Photovoltaics. Chem. Rev. 2017, 117, 796-837. [CrossRef]

50. Yun, J.; Wang, W.; Kim, S.M.; Bae, T.-S.; Lee, S.; Kim, D.; Lee, G.-H.; Lee, H.-S.; Song, M. Light trapping in bendable organic solar cells using silica nanoparticle arrays. Energy Environ. Sci. 2015, 8, 932-940. [CrossRef] 
51. Zhao, G.; Shen, W.; Jeong, E.; Lee, S.-G.; Yu, S.M.; Bae, T.-S.; Lee, G.-H.; Han, S.Z.; Tang, J.; Choi, E.-A.; et al. Ultrathin Silver Film Electrodes with Ultralow Optical and Electrical Losses for Flexible Organic Photovoltaics. ACS Appl. Mater. Interfaces 2018, 10, 27510-27520. [CrossRef] [PubMed]

52. Wang, Y.; Li, J.; Li, T.; Wang, J.; Liu, K.; Jiang, Q.; Tang, J.; Zhan, X. Black Phosphorous Quantum Dots Sandwiched Organic Solar Cells. Small 2019, 15, 1903977. [CrossRef] [PubMed]

53. Li, X.; Liang, Z.; Wang, H.; Qiao, S.; Liu, Z.; Jiang, H.; Chen, W.; Yang, R. Fluorinated D1(0.5)-A-D2(0.5)-A model terpolymer: Ultrafast charge separation kinetics and electron transfer at the fluorinated D/A interface for power conversion. J. Mater. Chem. A 2020, 8, 1360-1367. [CrossRef]

54. Zhao, G.; Shen, W.; Jeong, E.; Lee, S.-G.; Chung, H.-S.; Bae, T.-S.; Bae, J.-S.; Lee, G.-H.; Tang, J.; Yun, J. Nitrogen-Mediated Growth of Silver Nanocrystals to Form UltraThin, High-Purity Silver-Film Electrodes with Broad band Transparency for Solar Cells. ACS Appl. Mater. Interfaces 2018, 10, 40901-40910. [CrossRef] [PubMed]

(C) 2020 by the authors. Licensee MDPI, Basel, Switzerland. This article is an open access article distributed under the terms and conditions of the Creative Commons Attribution (CC BY) license (http://creativecommons.org/licenses/by/4.0/). 